\title{
Çocuk ve yetișkinde onko-tese uygulamaları: 2019 güncelleme
}

\author{
Onco-TESE applications in children and adults: 2019 update
}

\author{
A. Egemen Avcl ${ }^{\top}$, Mehmet Murad Basar²®
}

\section{öz}

Günümüzde tümör tedavisindeki gelişmeler yaşam süresindeki artışla beraber yaşam kalitesinde de beklentilerin yükselmesine yol açmıştır. Özellikle, erkeklerin adölesan dönemi ve sonrasında karşılaşabileceği testis tümörü ve lenfoma gibi non-genitoüriner tümörlerin cerrahi, kemoterapi ve radyoterapi ile tedavisi sperm yapımında bozulmaya neden olabilir. Tedavi öncesi sperm dondurulması gelecekte fertilitenin sağlanabilmesi için son derece önemlidir. Ancak, bu hastaların önemli bir kısmında azoospermi veya kriptozoospermi eşlik edebilmektedir. Bu durumda testisten mikrodiseksiyon yöntemi ile sperm arama işlemi gerçekleştirilmesi gereklidir. Bu işlem onko-TESE olarak adlandırılır.

Anahtar Kelimeler: Azoospermi, Onko-TESE, Testis tümörü
K anser gerek çeşitli patofizyolojik mekanizmalar yoluyla gerekse daha sonrasinda uygulanan kemoterapi/ radyoterapi gibi ek tedavilerin sitotoksik yan etkisiyle fertiliteyi olumsuz yönde etkiler. Primer testiküler kanserlerin lokal etkileri sonucu hem ipsilateral hem de kontralateral testiste fonksiyonu bozabilir. Gerek genitoüriner maligniteler gerekse non-genitoüriner maligniteler hipotalamo-hipofiz-gonadal aks üzerine etki ederek spermatogenezi düzenleyen endokrin fonksiyonları da bozabilir. ${ }^{[1]}$ Diğer taraftan, sistemik inflamasyon ve tümöre bağlı sitotoksik otoimmün yanıt da spermatogenezi olumsuz yönde etkilemektedir. Ayrıca, kanser ve tedavisi ile ilişkili psikolojik morbidite de hastada cinsel işlev bozukluğu ile üreme po-

${ }^{7}$ Memorial Ataşehir Hastanesi, Üroloji Bölümü, i̇stanbul, Türkiye

${ }^{2}$ Memorial Şişli Hastanesi, Üroloji-Androloji Bölümü, İstanbul, Türkiye

Yazışma Adresi/ Correspondence:

Prof. Dr. Mehmet Murad Basar

Memorial Şişli Hastanesi, Üroloji, 34385 İstanbul, Türkiye

Tel:

+905336557623

E-mail: muradbasar66@hotmail.com

Geliş/ Received: $\quad 18.08 .2019$

Kabul/ Accepted: $\quad 29.08 .2019$

\section{ABSTRACT}

Recently, developments in the cancer treatment have led to increased quality of life as well as lifetime expectations. Especially, surgical, chemotherapeutic and/or radiotherapeutic treatment of testicular or non-genitourinary tumors such as lymphoma/leukemia which observed in men in adolescent and adulthood period can cause to decreased sperm production. Sperm freezing before the treatment is extremely important for the salvage of future fertility. However, an important part of the patients can be accompanied by azoospermia or cryptozoospermia. In this case, it is necessary to perform sperm search from the testicle by microdissection method. This procedure is called as Onco-TESE.

Keywords: Azoospermia, Onco-TESE, Testis tumour

tansiyeli üzerine negatif etki yaratmaktadır. ${ }^{[2,3]}$ Onkolojik cerrahideki tüm gelişmelere rağmen radikal pelvik cerrahi sırasında ereksiyon ve ejakülasyonu kontrol eden parasempatik ve sempatik sinirler etkilenmekte ve bunun sonucunda cinsel fonksiyon bozukluğu ve ejakülasyon sorunları ortaya çıkmaktadır. ${ }^{[4,5]}$ Birçok kemoterapötik ajan doza bağlı bir şekilde spermatotoksiktir. Bu ilaçlar içinde özellikle alkali edici ajanlar en zararlı olanlarıdır. ${ }^{[6]} \mathrm{Ne}$ yazık ki bu ajanlar, özellikle çocuklu çağı maligniteleri arasında olan lösemi ve lenfoma başta olmak üzere pek çok malignitede sıklıkla kullanılmaktadır. Benzer şekilde, radyasyon tedavisi de doza bağımlı olarak spermatogenezde bozulmaya yol açar. ${ }^{[7,8]}$ Radyoterapi ve kemoterapi tedavilerini takiben semen parametreleri nadiren erkeklerde birkaç ay ile 1-2 yıl içinde düzelebilirken, önemli bir oranda erkekte kalıcı azoospermiye neden olur.

Son yıllarda, kanser hastalıklarının erken tanı yöntemleri ve tedavilerindeki gelişmeler her yaştaki erkek için uzun süreli hayat beklentisine yol açmıştır. Bu gelişmelere paralel olarak yüksek yaşam kalitesi bilincinin artması da eşlik 
etmektedir. Fertilitenin korunması bu açıdan, yeni tanı konmuş kanser hastalarını değerlendirirken hayat kalitesinin planlamasında, özellikle genç yaş grubu erkek hastalarda önemli bir hale gelmiştir.

Testis tümörü infertil popülasyonda \%1-1,5 oranında izlenir ve normal popülasyondan 20 kat daha fazladır. Vakaların \%6-24'ü ilk tanı sırasında azoospermiktir. Olguların \%1-2'si bilateraldir. Heterokronöz testiküler tümörler dört kat daha sık izlemektedir. Seminom heterokronöz tümörlerin \%47'sini, ipsilateral tümörlerin ise \%67'sini oluşturur. ${ }^{[9]}$ Testiküler germ hücreli tümörü olan erkeklerin \%24'ünde etkilenmemiş karşı taraf testiste de spermagoegenez bozulmaktadır. ${ }^{[10]} \mathrm{Bu}$ durum tümörün sistemik etkisi ve testiküler disgenetik sendrom ile ilişkili olarak yorumlanmaktadır. ${ }^{[11]}$

Testiküler tümörler spermatogenez üzerine lokal etkiler göstermektedir. En yüksek spermogenetik defekt maligniteye en yakın yerdeki tümörlerde izlenir. Ancak, aynı durum benign tümörler için söz konusu değildir. ${ }^{[12]}$ Özellikle 4 cm'den büyük seminomötöz ve non-seminmatöz germ hücreli tümörler spermatogenezde önemli azalma ile birliktedir. ${ }^{[13-15]}$

Tümör ve infertilite arasındaki ilişki çeşitli mekanizmalar ile açıklanmaya çalışılmaktadır ${ }^{[13,16,17]}$ : i) Tümör tarafından lokal olarak salınan $\beta$-hCG, $\alpha$-fötoprotein, LDH gibi maddeler ile spermatogenezin etkilenmesi; ii) Tümörün neden olduğu anti-sperm antikorlar ile kan-testis bariyerinin hasarlanması; iii) Hormonal aktif tümörlerde hipotalomo-hipofizer aksın etkilenmesi; iv) Tümöre bağlı ateş nedeni ile spermatogenezin bozulması; Yapılan bazı çalışmalarda tümör marker düzeyi ile sperm sayısı arasında negatif korelasyon olduğuna ait veriler de vardır.

Sonuçta tümör tedavisindeki son yıllardaki dramatik değişimler sonucunda kötü prognoz kriteri olan olgularda dahi yaşam süresinin uzaması, özellikle genç hastalarda dikkatin fertilitenin korunması üzerine çevirmiştir. Bu nedenle gonadotoksik tedavi uygulanmadan önce ejakülat sperminin dondurulması uygun hastalarda önerilen bir yaklaşımdır. Ancak, sperm sayısı çok az olan veya azoospermik olan olgularda bu mümkün olmamaktadır. Diğer taraftan kemoterapi veya radyoterapi alan olgularda bir süre için geçici azoospermi gelişebilmektedir. ${ }^{[18]}$ Ayrıca, ek terapilerin sperm DNA'sı üzerine olumsuz etkileri de mevcuttur. ${ }^{[19,20]}$ Bazı olgularda bu tedavilerin cerrahiden hemen sonra acilen uygulanması gerekebilir $\mathrm{Bu}$ nedenle sperm eldesinin erken dönmede yapılması sağlıklı spermin sağlanması ve sonraki dönemde uygulanacak yardımcı üreme tekniklerinin başarısı için oldukça önemlidir. ${ }^{[18]}$ Bununla birlikte kemoterapi/radyoterapi sonrası testisten mikroskobik testiküler sperm ekstraksiyonu (mikro TESE) yöntemi ile sperm eldesinin mümkün olduğunu bildiren çalışmalar da vardir. ${ }^{[21-23]}$

Non-obstrüktif azoospermi olgularında standart yaklaşım mikroskop altında sperm kanallarının 15-20 büyütme ile incelenerek dilate tubüllerin değerlendirildiği ve bu alanlardan doku örneğinin alındığı mikro-TESE yöntemidir. Bu yöntem ile doku hasarı 70 kat azaltılırken; sperm elde etme olasılığ1 \%40-60 olarak bildirilmektedir. ${ }^{[24,25]}$ Benzer uygulama azoospermia saptanan testis tümörlü olgularda da uzun zamandır uygulanmaktadır. ${ }^{[26-28]} \mathrm{Bu}$ yöntemin amacı etkilenen testisin tümörsüz alanında sperm eldesini sağlamaktır. Orşiektomi esnasında eksize edilmiş testislerden sperm ekstraksiyonunu içeren bu yöntemle “Onko-TESE” kavramı ilk defa Schrader tarafindan tanımlanmış ve o zamandan beri, azoospermili hastalarda orşiektomi ile aynı zamanda uygulanan fertilte koruyucu bir prosedür olarak kabul edilmektedir. ${ }^{\text {[29-32] }}$

Testis kanserli olgularda onko-TESE işlemi 3 türde değerlendirilir: I) Tek taraflı testis tümörü için orşiektomi esnasında tümörlü testisten mikro-TESE ile sperm eldesi; II) Bilateral testiküler tümörlü olgularda daha sağlıklı olan testisten sperm eldesi; III) Daha önce orşiektomi yapılmış tek taraflı testis olgusunda metakronöz tümör gelişiminde sperm eldesi. ${ }^{[33]}$

Onko-TESE, inguinal orşiektomi operasyonu sırasında, testis operasyon masasına alındıktan sonra ve mikroskop eşliğinde yapılır. Sadece testisin tümör içermeyen bölgesinin tunika albugineası açılarak tümörün patolojik tanısını mümkün olduğunca korunmaya çalışılmalıdır. Orşiektomi sonrası testiste tümör içermeyen alanlarda sperm saptanamayan hastalarda ameliyat öncesi onamı varsa diğer testiste de sperm arama işlemine devam edilebilir.

Onko-TESE ile testisten sperm eldesi \%62-80 arasında değişmektedir. ${ }^{[13-15]}$ Başarıyı etkileyen faktörler kriptorşidizm öyküsünün varlığı, tümör boyutu ve tümörün evresidir. Yapılan bir çalışmada tümör çapı ile sperm eldesi arasında ters yönlü ilişki olduğu belirtilmiştir. Jeremy ark. tümör çapı $1 \mathrm{~cm}, 2 \mathrm{~cm}$ ve $5 \mathrm{~cm}$ olan olgularda sperm elde etme oranı sırası ile $\% 86, \% 81$ ve $\% 57$ olarak göstermişlerdir. ${ }^{[13]}$

Onko-TESE'nin avantajı spermin histopatolojik inceleme ile kaybedilecek olan dokudan maksimum kapasite ile elde edilmesine olanak sağlamasıdır. Yine bu yöntem ile etkilenmemiş karşı taraf testiste cerrahi bir girişim yapılmayarak testiküler hasarın önüne geçilebilmektedir. Böylece azoospermik tek testisli olgularda veya iki taraflı senkronize testis tümörü gelişen azoospermik olgularda fertilitenin elde edilmesinde önemli katkı sağlanabilmektedir. Diğer 
taraftan sperm hücrelerinin dondurulmuş olduğunun bilinmesi gelecekte kullanılıp kullanılmadığının önemi olmaksızın hastalarda yaşam kalitesini ve güven duygusunu artırır. Ayrıca, bu prosedürle kemoterapinin sperm üzerindeki olası teratojenik etkileri de önlenmiş olur. ${ }^{[34-36]}$

Önceki çalışmalarda küçük çaplı tümörlerde ve tümör sınırından uzak alanda en iyi spermatogenetik aktivite ile sperm elde edilebildiği belirtilmiş olmasına rağmen, onko-TESE'nin bu konudaki etkisi halen daha belirgin değildir. ${ }^{[37]}$ Yapılan bazı çalışmalarda kanseröz alanda da normal spermatogenez içiren pek çok bölgenin olduğu gösterilmiştir. ${ }^{[38]}$

Onko-TESE uygulaması sadece testis tümörleri için değil spermatogenez üzerinde en belirgin toksik etkisi olan alkalize ajanların sık kullandığı lenfoma/lösemi hastaları için de önemli bir uygulama olarak değerlendirilmelidir. Genellikle çocukluk çağı tümörleri olarak bilinen bu tümörler spermatogenezin henüz başladığı erken post-pubertal dönmede veya yetişkin yaşlarda da ortaya çıkabilmekte ve bu olgularda ya puberte sonrasında olduğu gibi elde edilen sperm sayısı çok düşük olabilmekte ya da eş zamanlı azoopsermi izlenebilmektedir. Bu olgulara da kemoterapi/radyoterapi öncesi in vivo onko-TESE uygulaması ile sperm eldesi fertilitenin korunması açısından önemli katkı sağlayacaktır. Ayrıca, bu hastalarda gerek testiküler tutulum ile gerekse daha önce açıklanan tümör toksik mekanizmalar ile de spermatogenezin bozulabileceğini unutmamak gerekir.

Onko-TESE'nin avantajları yanında dezavantajları ve komplikasyonlarının da olduğu açıktır. Daha önce orşiektomi yapılmış tek testisli bir hastada nadiren de olsa mikro-TESE operasyonun hematom, enfeksiyon ve atrofi gibi olası komplikasyonları hakkında hastaya mutlaka bilgi verilmelidir. Oluşabilecek bir diğer komplikasyon ise hipogonadizm gelişmesi ve bunun sonucunda hastanın ömür boyu testosteron tedavisi alabileceği bir durumla karşılaşmasıdır. Diğer taraftan, onko-TESE ile elde edilen ve dondurulan spermlerin hastanın klinik prognozu nedeniyle gelecekte kullanılıp kullanılmayacağının bir garantisi yoktur. Mevcut hastalığın prognozu iyi olsa bile daha sonra saptanan ve altta yatan ek bir genetik sorun nedeniyle mevcut spermler kullanılamayabilir. Ayrıca, hastada zaman içinde spontan spermatogenetik aktive başlayarak tekrar ejakülatta sperm elde edilebilir ve bu sperrmler ile yardımcı üreme tekniği uygulanabilir.

Onko-TESE prosedürü yanı sıra spermatogenetik aktiviteyi korumaya yönelik bir takım uygulamalarda da yapılmaktadır. Yapılan deneysel çalışmalarda hipotalamik-hipofiz-gonadal aksin gonadotropin salgilayan hormon agonistleri ile hormonal olarak baskılanmasının spermatogonia gelişimini geri dönüşümlü baskılayarak spermatogenezde iyileşmesini sağladığı ileri sürülmüştür. ${ }^{[39]}$ Bununla birlikte, bu çalışmaların sonuçları insanlarda doğrulanmamış ve bu nedenle erkeklerde hormonal gonadoproteksiyon önerilmememiştir. ${ }^{[40,41]}$ Buna karşılık, spermatogonial kök hücrelerin sonradan otolog transplantasyonu ile testiküler doku kriyoprezervasyonu, özellikle prepubertal hasta için önem teşkil emektedir. ${ }^{[42,43]}$ Çok sayıda çalışmada testis dokusundan izole edilmiş ve otolog transplantasyon için uygun germ hücrelerinin bulunduğu gösterilmiştir. ${ }^{[44,45]}$ Teorik olarak, bu teknikler sperm veya olgun gametlerin kriyoprezervasyon için uygun olmadığı prepubertal erkekler için idealdir. Bununla birlikte, bu konuda araştırmalar devam etmektedir ve sadece bir kısmı devam etmekte olan klinik bir çalışma bağlamında sürdürülmelidir.

Yaklaşım ne olursa olsun, kanser hastalarında spermin dondurulması ve gelecekteki kullanımı hakkında uygun danışmanlık, fertilitenin korunmasında temeldir. Ejakülatta sperm izlenmeyen olgularda mikro-TESE işlemi yanı sıra, testiküler tümörlü olgularda orşiektomi sonrası testis dokusunda mikroskop altında testis histolojisini bozmadan ve tümöre uzak alanda yapılan mikro disseksiyon TESE işlemi, yani onko-mikro-TESE ile hastalara gelecekte çocuk sahibi olabilme konusunda büyük avantaj sağlamaktadır.

\section{Hakem Değerlendirmesi}

Dış bağımsız

Çıkar Çatışması

Yazarlar çıkar ilişkisi olmadığını beyan etmişlerdir.

Finansal Destek

Herhangi bir mali destek alınmamıştır.

\section{Peer-review}

Externally peer-reviewed.

Conflict of Interest

No conflict of interest was declared by the authors.

Financial Disclosure

No financial disclosure was received.

\section{KAYNAKLAR}

1. Meirow D, Schenker JG. Cancer and male infertility. Hum Reprod 1995;10:2017-22. [CrossRef]

2. Theas MS, Rival C, Jarazo-Dietrich S, Jacobo P, Guazzone VA, Lustig L. Tumour necrosis factor-alpha released by testicular macrophages induces apoptosis of germ cells in autoimmune orchitis. Hum Reprod 2008;23:1865-72. [CrossRef]

3. van Basten JP, van Driel MF, Hoekstra HJ, Sleijfer DT, van de Wiel $\mathrm{HB}$, Droste JH, et al. Objective and subjective effects of treatment for testicular cancer on sexual function. BJU Int 1999;84:671-8. [CrossRef]

4. Rice KR, Cary CK, Masterson TA, Foster RS. Surgery of testicular tumors. In: Wein AJ, Kavoussi LR, Partin AW, Peters CA, editors. Campbell-Walsh Urology. Philadephia: Elsevier; 2012. pp.815-37.

5. Allaf ME, Kavoussi LR. Laparoscopic and robotic assisted repropetitoneal lympadenonectomy for testicular tumors. In: Wein AJ, Kavoussi LR, Partin AW, Peters CA, editors. Campbell-Walsh Urology. Philadephia: Elsevier; 2012. pp.838-45. 
6. Green DM, Liu W, Kutteh WH, Ke RW, Shelton KC, Sklar CA, et al. Cumulative alkylating agent exposure and semen parameters in adult survivors of childhood cancer: a report from the St Jude Lifetime Cohort Study. Lancet Oncol 2014;15:1215-23. [CrossRef]

7. Hansen PV, Trykker H, Svennekjaer IL, Hvolby J. Long-term recovery of spermatogenesis after radiotherapy in patients with testicular cancer. Radiother Oncol 1990;18:117-25. [CrossRef]

8. Shalet SM. Effect of irradiation treatment on gonadal function in men treated for germ cell cancer. Eur Urol 1993;23:148-51. [CrossRef]

9. Klatte T, de Martino M, Arensmeier K, Reiher F, Allhoff EP, Klatte D. Management and outcome of bilateral testicular germ cell tumors: a 25-year single center experience. Int J Urol 2008;15:821-6. [CrossRef]

10. Berthelsen JG. Testicular cancer and fertility. Int J Androl 1987;10:371-80. [CrossRef]

11. Skakkebaek NE, Rajpert-De Meyts E, Main KM. Testicular dysgenesis syndrome: an increasingly common developmental disorder with environmental aspects. Hum Reprod 2001;16:9728. [CrossRef]

12. Moody JA, Ahmed K, Yap T, Minhas S, Shabbir M. Fertility management in testicular cancer: the need to establish a standardized and evidence-based patient-centric pathway. BJU Int 2019;123:160-72. [CrossRef]

13. Delouya G, Baazeem A, Boman JM, Violette P, Saad F, Zini A Identification of spermatozoa in archived testicular cancer specimens: implications for bench side sperm retrieval at orchiectomy. Urology 2010;75:1436-40. [CrossRef]

14. Choy JT, Wiser HJ, Bell SW, Cashy J, Brannigan RE, Köhler TS. Predictors of spermatogenesis in orchiectomy specimens. Urology 2013;81:288-92. [CrossRef]

15. Shoshany O, Shtabholtz Y, Schreter E, Yakimov M, Pinkas H, Stein A, et al. Predictors of spermatogenesis in radical orchiectomy specimen and potential implications for patients with testicular cancer. Fertil Steril 2016;106:70-4. [CrossRef]

16. Tvrda E, Agarwal A, Alkuhaimi N. Male reproductive cancers and infertility: a mutual relationship. Int J Mol Sci 2015;16:7230-60. [CrossRef]

17. Ostrowski KA, Walsh TJ. Infertility with testicular cancer. Urol Clin North Am 2015;42:409-20. [CrossRef]

18. Furuhashi K, Ishikawa T, Hashimoto H, Yamada S, Ogata S, Mizusawa Y, et al. Onco-testicular sperm extraction: testicular sperm extraction in azoospermic and very severely oligozoospermic cancer patients. Andrologia 2013;45:107-10. [CrossRef]

19. Larson KL, DeJonge CJ, Barnes AM, Jost LK, Evenson DP. Sperm chromatin structure assay parameters as predictors of failed pregnancy following assisted reproductive techniques. Hum Reprod 2000;15:1717-22. [CrossRef]

20. Bungum $M$, Humaidan $P$, Spano $M$, Jepson K, Bungum L, Giwercman A. The predictive value of sperm chromatin structure assay (SCSA) parameters for the outcome of intrauterine insemination, IVF and ICSI. Hum Reprod 2004;19:1401-8. [CrossRef]

21. Damani MN, Master V, Meng MV, Burgess C, Turek P, Oates RD. Postchemotherapy ejaculatory azoospermia: fatherhood with sperm from testis tissue with intracytoplasmic sperm injection. J Clin Oncol 2002;20:930-6. [CrossRef]

22. Mesaguer M, Garrido N, Remohí J, Pellicer A, Simón C, Martínez-Jabaloyas JM, Gil-Salom M. Testicular sperm extraction (TESE) and ICSI in patients with permanent azoospermia after chemotherapy. Hum Reprod 2003;18:1281-5. [CrossRef]
23. Hsiao W, Stahl PJ, Osterberg EC, Nejat E, Palermo GD, Rosenwaks Z, Schlegel PN. Successful treatment of postchemotherapy azoospermia with microsurgical testicular sperm extraction: the Weill Cornell experience. J Clin Oncol 2011;29:1607-11. [CrossRef]

24. Schlegel PN. Testicular sperm extraction: microdissection improves sperm yield with minimal tissue excision. Hum Reprod 1999;14:131-5. [CrossRef]

25. Osterberg EC, Ramasamy R, Masson P, Brannigan RE. Current practices in fertility preservation in male cancer patients. Urol Ann 2014;6:13-7. [CrossRef]

26. Binsaleh S, Sircar K, Chan PT. Feasibility of simultaneous testicular microdissection for sperm retrieval and ipsilateral testicular tumor resection in azoospermic men. J Androl 2004;25:867-71. [CrossRef]

27. Choi BB, Goldstein M, Moomjy M, Palermo G, Rosenwaks $Z$, Schlegel PN. Births using sperm retrieved via immediate microdissection of a solitary testis with cancer. Fertil Steril 2005;84:1508.e1-4. [CrossRef]

28. Descombe L, Chauleur C, Gentil-Perret A, Aknin-Seifer I, Tostain J, Levy R. Testicular sperm extraction in a single cancerous testicle in patients with azoospermia: a case report. Fertil Steril 2008;90:443.e1-4. [CrossRef]

29. Schrader M, Müller M, Sofikitis N, Straub B, Krause H, Miller K. Onco-tese": testicular sperm extraction in azoospermic cancer patients before chemotherapy-new guidelines? Urology 2003;61:421-5. [CrossRef]

30. Safsaf A, Sibert L, Cleret JM, Perdrix A, Milazzo JP, Gobet F, et al. Concomitant unilateral and synchronous bilateral testis cancer in azoospermic dizygotic twins: differential management of fertility preservation. Fertil Steril 2011;95:2434.e11-3. [CrossRef]

31. Haddad N, Al-Rabeeah K, Onerheim R, Zini A. Is ex vivo microdissection testicular sperm extraction indicated for infertile men undergoing radical orchiectomy for testicular cancer? Case report and literature review. Fertil Steril 2014;101:956-9. [CrossRef]

32. Lujan S, Guzman-Ordaz D, Rogel R, Broseta E, Pellicer A, Boronat F. Onco-TESE: Obtaining spermatozoa after radical orchiectomy for testicular tumour and azoospermia. Actas Urol Esp 2016;40:64-7. [CrossRef]

33. Hamano I, Hatakeyama S, Nakamura R, Fukuhara R, Noro D, Seino $\mathrm{H}$, et al. Onco-testicular sperm extraction (Onco-TESE) from a single testis with metachronous bilateral testicular cancer: a case report. Basic Clin Androl 2018;28:1. [CrossRef]

34. Byrne J. Long-term genetic and reproductive effects of ionizing radiation and chemotherapeutic agents on cancer patients and their offspring. Teratology 1999;59:210-5. [CrossRef]

35. Trasler JM, Hales BF, Robaire B. Paternal cyclophosphamide treatment of rats causes fetal loss and malformations without affecting male fertility. Nature 1985;316:144-6. [CrossRef]

36. Sega GA. Adducts in sperm protamine and DNA vs. mutation frequency. Prog Clin Biol Res 1991;372:521-30.

37. Suzuki K, Shin T, Shimomura Y, Iwahata T, Okada $H$. Spermatogenesis in tumor-bearing testes in germ cell testicular cancer patients. Hum Reprod 2015;30:2853-8. [CrossRef]

38. Bulbul MA, Bachir BG. Testis-Sparing Surgery: Balancing Cancer Control with Fertility Preservation. In: Majzoub A, Agarwal A, editors. The Complete Guide to Male Fertility Preservation. Cham: Springer; 2018. pp.93-103.

39. Meistrich ML, Shetty G. Hormonal suppression for fertility preservation in males and females. Reproduction 2008;136:691701. [CrossRef] 
40. Peccatori FA, Azim HA, Orecchia R, Hoekstra HJ, Pavlidis N, Kesic V, Pentheroudakis G. Cancer, pregnancy and fertility: ESMO Clinical Practice Guidelines for diagnosis, treatment and follow-up. Ann Oncol 2013;24(Suppl 6):vi160-70. [CrossRef]

41. Oktay K, Harvey BE, Partridge AH, Quinn GP, Reinecke J, Taylor HS, et al. Fertility preservation in patients with cancer: ASCO clinical practice guideline update. J Clin Oncol 2018;36:19942001. [CrossRef]

42. Ethics Committee of the American Society for Reproductive Medicine. Fertility preservation and reproduction in patients facing gonadotoxic therapies: an Ethics Committee opinion. Fertil Steril 2018;110:380-6. [CrossRef]
43. Coccia PF, Pappo AS, Altman J, Bhatia S, Borinstein SC, Flynn J, et al. Adolescent and young adult oncology, version 2.2014. J Natl Compr Canc Netw 2014;12:21-32. [CrossRef]

44. Brook PF, Radford JA, Shalet SM, Joyce AD, Gosden RG. Isolation of germ cells from human testicular tissue for low temperature storage and autotransplantation. Fertil Steril 2001;75:269-74. [CrossRef]

45. Johnson EK, Finlayson C, Rowell EE, Gosiengfiao Y, Pavone ME, Lockart B, et al. Fertility preservation for pediatric patients: current state and future possibilities. J Urol 2017;198:186-94. [CrossRef] 